\title{
Differential expression of skeletal muscle mitochondrial proteins in yak, dzo, and cattle: a proteomics-based study
}

\author{
Ling LONG ${ }^{1) *}$, Yipan ZHU ${ }^{2)}$, Zhenzi LI'), Haixia ZHANG ${ }^{3)}$, Lixia LIU') and \\ Jialin $\left.B A\right|^{3)}$ \\ ${ }^{1)}$ College of Life Science and Engineering, Northwest Minzu University, Lanzhou 730124, China \\ 2) State Key Laboratory of Medicinal Chemical Biology and College of Pharmacy, \\ Tianjin Key Laboratory of Molecular Drug Research, Nankai University, Tianjin 300071, China \\ ${ }^{3)}$ Key Laboratory of Bioengineering \& Biotechnology of State Ethnic Affairs Commission, \\ Northwest Minzu University, Lanzhou 730124, China
}

\section{J. Vet. Med. Sci.}

82(8): 1178-1186, 2020

doi: 10.1292/jvms.19-0218

Received: 6 May 2019

Accepted: 22 May 2020

Advanced Epub:

9 July 2020

\begin{abstract}
Changes in yak mitochondria by natural selection in a hypoxic environment could be utilized to understand adaptation to low-oxygen conditions. Therefore, the differences in proteome profile of skeletal muscle mitochondria from yak, dzo, and cattle were analyzed by mass spectrometry, which were then classified into 3 groups, comparing between yak and dzo, yak and cattle, and dzo and cattle. 376 unique mitochondrial proteins were identified, including 192,191 , and 281 proteins in the yak-dzo, yak-cattle, and dzo-cattle groups, respectively. NRDP1 and COQ8A were expressed at higher levels in yak and dzo compared to those in cattle, indicating higher endurance capacity of yak and dzo in a low-oxygen environment. Gene Ontology (GO) terms of biological processes were significantly enriched in oxidation-reduction process, and that of molecular functions and cellular component were enriched in oxidoreductase activity and the mitochondrion, respectively. The most significantly affected pathways in Kyoto Encyclopedia of Genes and Genomes (KEGG) analysis were Parkinson's disease, Huntington's disease, and oxidative phosphorylation between the yak-cattle and dzo-cattle groups; while metabolic pathways, citrate cycle, and carbon metabolism were significantly affected pathways in the yak-dzo group. ATP synthases, MTHFD1, MDH2, and SDHB were the most enriched hub proteins in the protein-protein interaction (PPI) network. These results indicated that mammals living at high altitudes could possibly possess better bioenergy metabolism than those living in the plains. The key proteins identified in the present study may be exploited as candidate proteins for understanding and fine-tuning mammalian adaptation to high altitudes.

KEY WORDS: cattle, dzo, proteomics, skeletal muscle mitochondrial proteins, yak
\end{abstract}


Proteomic analysis can be used to measure dynamic changes in protein components, with respect to their expression level, post-translational modifications, and protein-protein interactions, thereby revealing novel methods to assess protein function in the context of cellular behavior [37]. Owing to the advantage of utilizing proteomics for various applications, including protein identification, this technology is widely applied in a variety of scientific fields. Mitochondria are relatively independent organelles and are easily purified for proteomic analysis; therefore, mitochondrial proteins are ideal targets for proteomic research compared to total proteins from whole cells $[10,28,36]$.

Yaks are adapted to low-oxygen environments, and their genetic characteristics have been conserved due to the geographical isolation of the Tibetan plateau [26]. Changes in the yak mitochondria are due to natural selection in a hypoxic environment, therefore this animal may be utilized as a model to gain a better understanding of hypoxic adaptations. In this study, we performed a comparative proteomic analysis of the mitochondrial proteins from yak, dzo, and cattle to explore differentially expressed proteins with related functions and pathways, and construct a protein-protein interaction network. Based on this, we could reveal a genetic mechanism for low-oxygen adaptation and provide new clues for understanding the mitochondrial function.

\section{MATERIALS AND METHODS}

\section{Ethics statement}

All procedures involved in the handling and care of animals were in accordance with the China Practice for the Care and Use of Laboratory Animals and were approved by China Zoological Society.

\section{Animals and sample collection}

The animals used in this study were from the grazing area of the village of Manrima (altitude, $3,585 \mathrm{~m}$; $102^{\circ} 04^{\prime} \mathrm{E}$ longitude; $33^{\circ} 45^{\prime} \mathrm{N}$ latitude). This region is characterized by its high altitude, low annual average temperature $\left(1.2^{\circ} \mathrm{C}\right)$, short agricultural season (from June to September), and substantial seasonal variation in food supply [21]. For the purpose of this study, the soil in this place was classified as alpine meadow. Nine yaks, nine cattle-yak hybrids (dzo), and nine Simmental beef cattle (18 months of age) were selected randomly from corresponding healthy herds. All species were provided with feed and water ad libitum. After slaughter, the gastrocnemius muscle was dissected and immediately frozen in liquid nitrogen for the extraction of mitochondrial protein. These samples were then used in a shotgun LC-MS/MS approach, combined with tandem mass tags (TMT) peptide labeling, for quantification of the proteome.

\section{Tissue and protein extraction}

We collected 9 skeletal muscle samples each from yak, dzo, and cattle and randomly mixed 3 samples from the same species into a single test sample. Therefore, each mixed sample consisted of 3 mixed skeletal muscle samples, one each from yak (1 g/ sample), dzo (1 g/sample), and cattle (1 g/sample). The 3 groups of yaks were named 126 (yak-1), 127N (yak-2), and 127C (yak-3). The 3 groups of dzo were named 128N (dzo-1), 128C (dzo-2), and 129N (dzo-3). The 3 groups of cattle were named 129C (cattle-1), 130N (cattle-2), and 130C (cattle-3). The group with mixed samples from all the species were named 131 (mixed) (Supplementary Fig. 1). Crude mitochondrial fractions (10 $\mu \mathrm{g} / \mathrm{sample})$ were extracted using a crude extraction and separation of mitochondria from animal cells/tissues kit (GMS10006.1 v.A; Genmed Scientifics Inc., Botson, MA, USA).

\section{Sodium dodecyl sulfate polyacrylamide gel (SDS-PAGE)}

SDS-PAGE was prepared by adding the separation gel to the assembled double-layered glass plate for casting gels, and the upper layer was kept covered in isopropanol at room temperature until the gel condensed. Then, the isopropanol was removed with a filter paper and the concentrated gel was added to the glass compartment, the pre-washed comb was inserted, and condensed at room temperature. Next, electrophoresis was performed by placing the prepared polyacrylamide gel in the electrophoresis tank and adding the running buffer and samples. The samples were initially run at a voltage of $60 \mathrm{~V}$ for $30 \mathrm{~min}$, and then at $120 \mathrm{~V}$ for another $2 \mathrm{hr}$ until the bromophenol blue was about $5 \mathrm{~mm}$ from the lower edge of the gel. Finally, the protein gel was separated and stained with Coomassie Brilliant Blue G-250.

\section{Protein labeling and MS analysis}

Trypsin (Mass Spectrometry Grade; Promega, Midison, WI, USA) was used to generate peptides. The target protein was dissolved in $8 \mathrm{M}$ urea $/ 50 \mathrm{mM}$ Tris- $\mathrm{HCl}(\mathrm{pH} 8) / 5 \mathrm{mM}$ DTT (e.g., $2.5 \mu \mathrm{g}$ of trypsin per $100 \mu \mathrm{g}$ of protein) and incubated at $37^{\circ} \mathrm{C}$ for $1 \mathrm{hr}$. Immediately before use, TMT label reagents (TMT10plex ${ }^{\mathrm{TM}}$ Isobaric Mass Tag Labeling Kit, $3 \times 0.8 \mathrm{mg}$, 90114 , Thermo Scientific, Waltham, MA, USA) were allowed to equilibrate to room temperature, added to $41 \mu l$ of anhydrous acetonitrile (ACN) in $0.8 \mathrm{mg}$ vials, and the reagent was allowed to dissolve for $5 \mathrm{~min}$ with occasional vortexing. $41 \mu l$ of the TMT label reagent was added to each 25-100 $\mu \mathrm{g}$ aliquot of the protein sample. The reaction was incubated for $1 \mathrm{hr}$ at room temperature. Then, $8 \mu \mathrm{l}$ of $5 \%$ hydroxylamine was added to the sample and incubated for $15 \mathrm{~min}$ to quench the reaction. The content of each tube was mixed by vortexing; it was centrifuged to collect the solution, and the sample was dried in a vacuum freeze dryer for TMT analysis.

\section{Reversed phase liquid chromatography (RPLC) analysis}

Dried samples were resuspended in $100 \mu l$ of buffer $\mathrm{A}\left(\mathrm{H}_{2} \mathrm{O}\right.$ with $0.1 \%$ formic acid (FA)). RPLC analysis was carried out using an Agilent 1200 HPLC System (Agilent, California, CA, USA); the HPLC column (Narrow-Bore, $2.1 \times 150 \mathrm{~mm}, 5 \mu \mathrm{m}$ ) was from 
Agilent. Separation was performed at a rate of $0.3 \mathrm{ml} / \mathrm{min}$ using a nonlinear binary gradient (Supplementary Table 1) starting with buffer A and transitioning to buffer B (ACN with $0.1 \%$ FA). The first fraction was collected during $0-5$ min, then each fraction was collected with a 4.5-min interval between 6-45 min, and the last fraction was collected from the 46-50-min timeframe, with a total of 10 fractions. Each fraction was dried in a vacuum freeze dryer for subsequent LC-MS/MS analysis.

\section{$L C-M S / M S$ analysis}

Samples were resuspended with nano-RPLC buffer A (0.1\% FA, 2\% ACN). Online nano-RPLC was carried out using the EASYnLC 1000 System (Thermo Scientific). The samples were loaded on a nano-RPLC trap column (PepMap100 C18, $3 \mu \mathrm{m}, 75 \mu \mathrm{m}$ $\times 20$-mm, nanoViper, Thermo Fisher Dionex, Waltham, MA, USA) and washed with the nano-RPLC buffer A at a rate of $2 \mu l /$ min for $10 \mathrm{~min}$. An elution gradient of $5-35 \% \mathrm{ACN}(0.1 \% \mathrm{FA})$ for $70 \mathrm{~min}$ was used in an analytical column (PepMap100 C18, $2 \mu \mathrm{m}, 75 \mu \mathrm{m} \times 150 \mathrm{~mm}$, nanoViper; Thermo Fisher Dionex). Data acquisition was performed on the Q Exactive System (Thermo Scientific) fitted with a Nanospray. The Q Exactive setup was operated using the data-dependent top-20 parameters with $70 \mathrm{k}$ resolution for full MS scan, $17.5 \mathrm{k}$ resolution for high energy collisional dissociation MS/MS scans, and a dynamic exclusion time of $30 \mathrm{sec}$. Full MS scans were acquired in the Q Exactive Orbitrap mass analyzer (Thermo Scientific) over a 300-1,800 m/z range with a mass resolution of 70,000 (at $200 \mathrm{~m} / \mathrm{z}$ ). The 12 most intense peaks at a charge state $\geq 2$ were fragmented in the high energy collisional dissociation collision cell with a normalized collision energy of $27 \%$. Tandem mass spectra were acquired in the same setup with a mass resolution of 35,000 at $200 \mathrm{~m} / \mathrm{z}$.

\section{Protein identification and quantification}

Spectral data files were analyzed using the Proteome Discoverer 1.3 software (Thermo Scientific) and the SEQUEST ${ }^{\circledR}$ search engine (Thermo Scientific), constrained with a precursor mass tolerance of $10 \mathrm{ppm}$ and fragment mass tolerance of $0.02 \mathrm{Da}$. Carbamidomethylation (+57.021 Da) of cysteine and TMT isobaric labeling (+229.163 Da) of lysine were set as static modifications, while TMT labeling of the peptide and protein N-termini, deamidation of asparagine and glutamine $(+0.984 \mathrm{Da})$, oxidation of methionine $(+15.996 \mathrm{Da})$, and formation of pyro-glutamate from glutamine on the peptide N-terminus $(-17.027 \mathrm{Da})$ were considered to be dynamic. Data was searched against a Swiss-Prot complete bovine database with a $1 \%$ false discovery rate (FDR) criteria. The TMT6plex quantification method available in the Proteome Discoverer 1.3 software was used to calculate reporter ratios with mass tolerances of $0.01 \mathrm{Da}$ without applying isotopic correction factors. Protein ratios were expressed as the median value of the ratios for all quantifiable spectra of the peptides pertaining to each protein.

\section{Functional and pathway enrichment analysis}

The biological functions of differentially expressed proteins were investigated by comparison with the Gene Ontology (GO) database (http://www.geneontology.org/). The GO enrichment analysis was based on the mainstream databases DAVID6.7 (http:// david.abcc.ncifcrf.gov/) and QuickGO (http://www.ebi.ac.uk/QuickGO/), which were used to describe the GO classification, annotation, and enrichment analysis of the different screened proteins. Information on the differentially expressed proteins was also obtained from the Kyoto Encyclopedia of Genes and Genomes (KEGG) database (http://www.kegg.jp/kegg/pathway.html), which could assess the signaling pathways. Based on the enrichment results, a customized horizontal version of the histogram was assembled using the significant vertical version of the top 10 entries in the column [13].

\section{PPI network construction}

Analysis of protein-protein interactions (PPI) was based on the STRING database (v11.0, https://string-db.org/), which is a database that details functional relationships between proteins, thereby allowing for prediction of functions. This system has enabled searching for interactions between known proteins and predicted ones, thereby uncovering the roles of the latter in cellular growth, development, metabolism, differentiation, and apoptosis $[14,20]$. In this study, we constructed a PPI network based on the STRING (http://string.embl.de/) and Cytoscape (http://www.cytoscape.org/) software, and visualized the distribution characteristics of the top 10 up- and down-regulated proteins [20,32].

\section{RESULTS}

\section{Identification of differentially expressed proteins}

Using proteomics-based methods, 576 mitochondrial proteins and 376 differentially expressed proteins (fold change $>1.2$ or $<0.6$ were set as cutoff values) were observed by LC-MS/MS analysis. The identified proteins were classified into 3 groups, namely the yak-dzo, yak-cattle, and dzo-cattle groups. The analysis identified 192 differentially expressed proteins in the yak-dzo group (33 upregulated and 159 downregulated proteins), 191 differentially expressed proteins in the yak-cattle group (115 upregulated and 76 downregulated proteins), and 281 differentially expressed proteins in the dzo-cattle group (231 upregulated and 50 downregulated proteins). Specific information regarding the differentially expressed proteins is shown in Supplementary Table 2 and the heat map of differentially expressed mitochondrial proteins is represented in Fig. 1.

\section{GO term enrichment analysis}

The GO enrichment analysis was performed using the David6.7 and the QuickGO databases for GO classification, annotation, and enrichment analysis of screened proteins. In the yak-dzo group, differentially expressed proteins were related to redox, small 


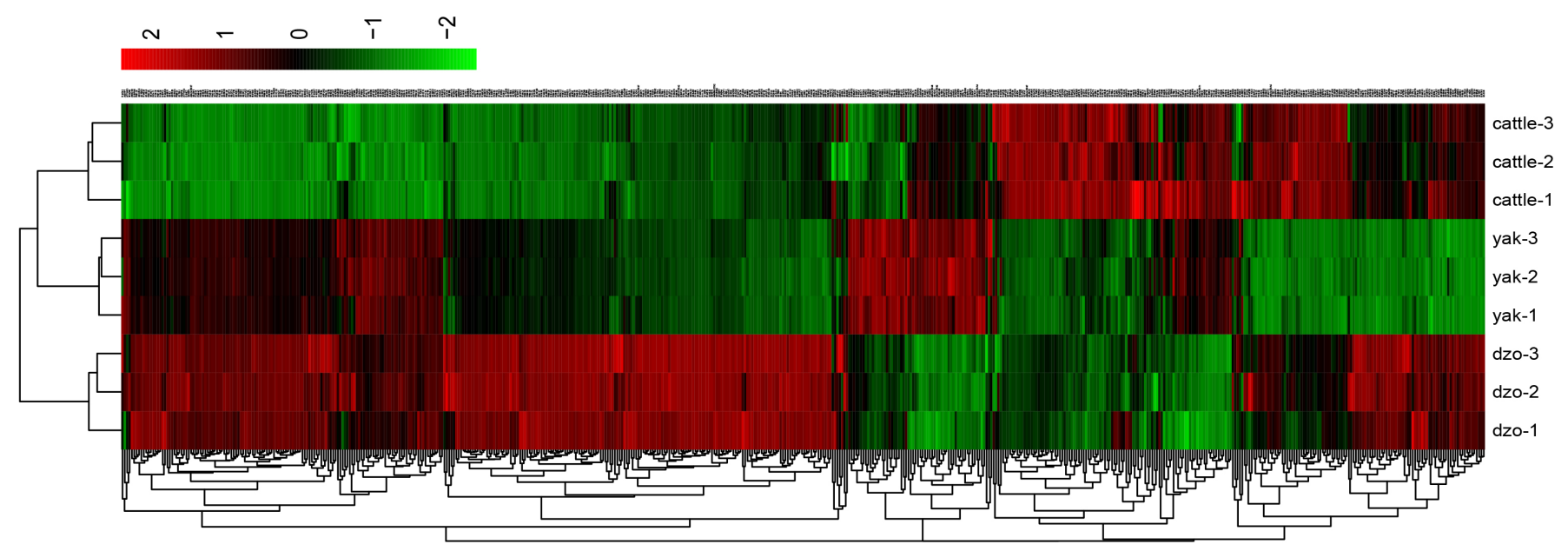

Fig. 1. Heatmap of mitochondrial proteins in yak, dzo, and cattle. Red, up-regulation; green, down-regulation.

molecule metabolism, and cellular respiration processes (Fig. 2A). The differentially expressed proteins in the yak-cattle group were enriched in redox processes and the electron transport chain (Fig. 2B). On the other hand, the differentially expressed proteins in the dzo-cattle group were enriched in cellular respiration, ATP metabolic, and redox processes (Fig. 2C). Using the GO cell component analysis, differentially expressed proteins were found to be significantly enriched in the mitochondrion in all 3 groups. Molecular functions in all the 3 groups were identified as important for oxidoreductase activity and hydrogen ion transmembrane transporter activity (Fig. 2).

\section{KEGG pathway analysis}

The most significantly enriched pathways in the 3 groups from KEGG analysis are shown in Fig. 3. Differentially expressed proteins in the yak-dzo group were enriched in metabolic pathways, including citrate cycle and carbon metabolism (Fig. 3A and Supplementary Table 3). However, in the yak-cattle and dzo-cattle groups, differentially expressed proteins were significantly enriched in those involved in Parkinson's disease, Huntington's disease, and oxidative phosphorylation (Fig. 3B and 3C and Supplementary Tables 4 and 5).

\section{PPI network construction}

Using information from the STRING database, the top 40 hub nodes were identified in the PPI network (Fig. 4 and Supplementary Tables 6-8). In the yak-dzo group, the top 3 hub proteins were malate dehydrogenase (MDH2), ATP synthase subunit beta (ATP5B), and methylenetetrahydrofolate dehydrogenase, cyclohydrolase and formyltetrahydrofolate synthetase 1 (MTHFD1) (Fig. 4A). In the yak-cattle group, the top 3 hub proteins were ATP synthase subunit O (ATP5O), ATP synthase subunit gamma (ATP5C1), and ATP synthase subunit d (ATP5H) (Fig. 4B). ATP5C1, ATP5O, and succinate dehydrogenase [ubiquinone] iron-sulfur subunit (SDHB) were the top 3 hub proteins in the dzo-cattle group (Fig. 4C).

\section{DISCUSSION}

Research into the molecular mechanisms that enable high-altitude adaptation in mammals of the plateau is important for preventing and treating hypoxia and related diseases $[2,3,12,17,19,25]$. The yak, an essential animal in Tibet, provides food, shelter, fuel, and transport for the local people, largely due to its ability to adapt to cold, low-oxygen, and low-atmospheric pressure environments. The differentiation of yaks and cattle dates back to 50,000 years, and both are classified as bovine species. The dzo is the offspring of yak and cattle, cows, or other common bovines [15]. The genomes of yaks and cattle have been sequenced, thereby enabling studies into yak-cattle hybrids for research on low-oxygen adaptation [6, 9, 30]. Many researches have focused on comparison of yaks and cattle at the level of nucleic acid sequences and genomics, but differences at the mitochondrial protein level have not been measured. Especially, those for the dzo remain to be examined. To explore the proteomic level differences in yak mitochondria and their role in low-oxygen adaptation mechanisms, a bioinformatics approach was utilized to compare yak, dzo, and cattle. This study identified 376 differentially expressed proteins, including 192 proteins in the yak-dzo group, 191 proteins in the yak-cattle group, and 281 proteins in the dzo-cattle group.

E3 ubiquitin-protein ligase NRDP1 was the protein with the most significantly different expression pattern in both the yak-dzo and yak-cattle groups. The protein encoded by the RNF41 gene contains a really interesting new gene (RING) finger domain, which is a motif present in a variety of functionally distinct proteins and is known to be involved in protein-protein interactions and in maintaining stability mediated by the ubiquitin-specific protease 8 (USP8) [42]. CLEC16A could form an ubiquitindependent tripartite complex with NRDP1 (RNF41) and USP8. Maintenance of the CLEC16A-NRDP1-USP8 mitophagy complex 


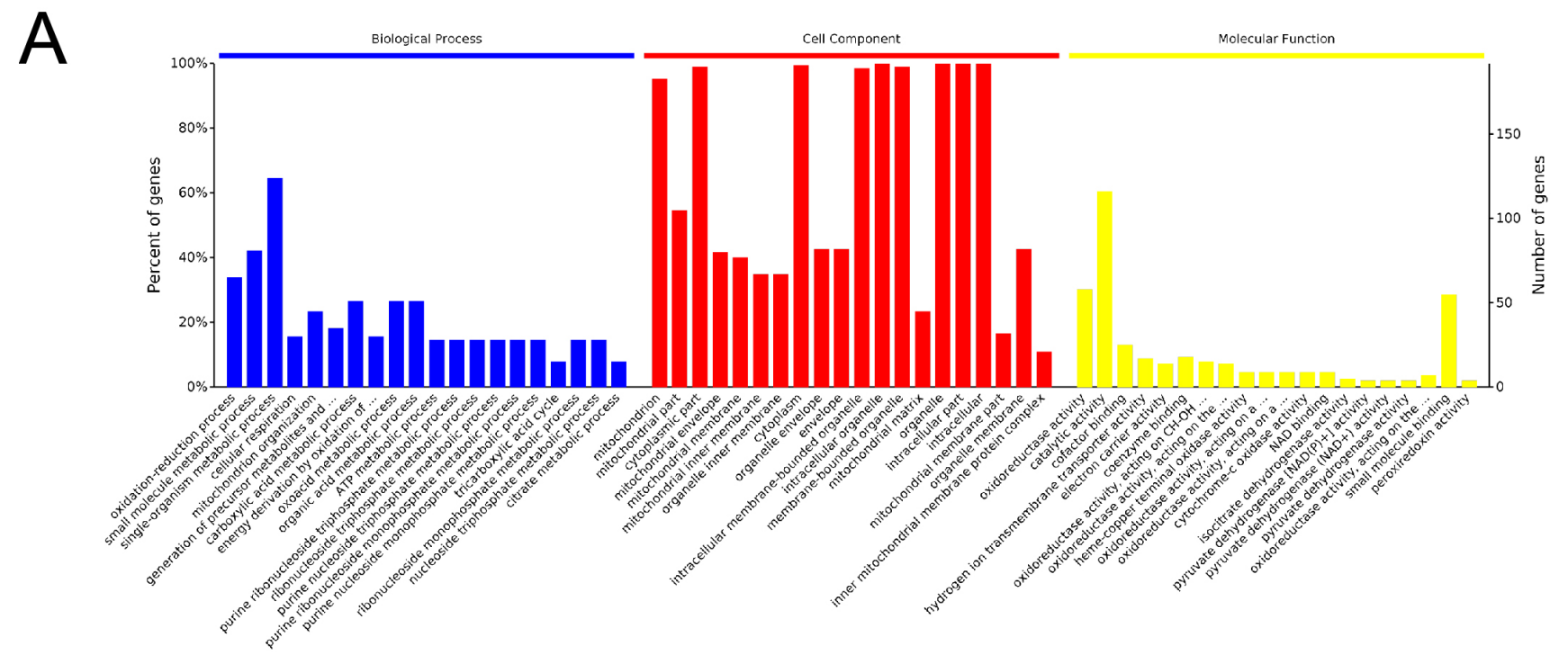

B

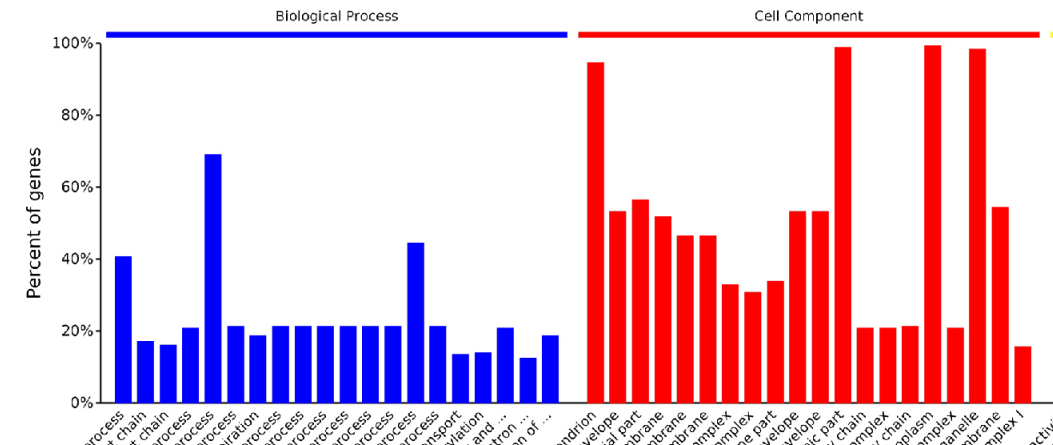

Molecular Function

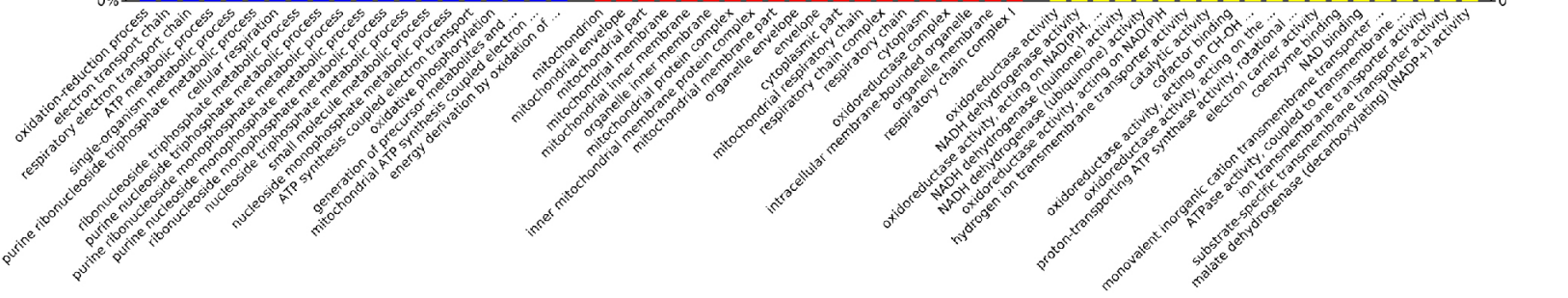

C
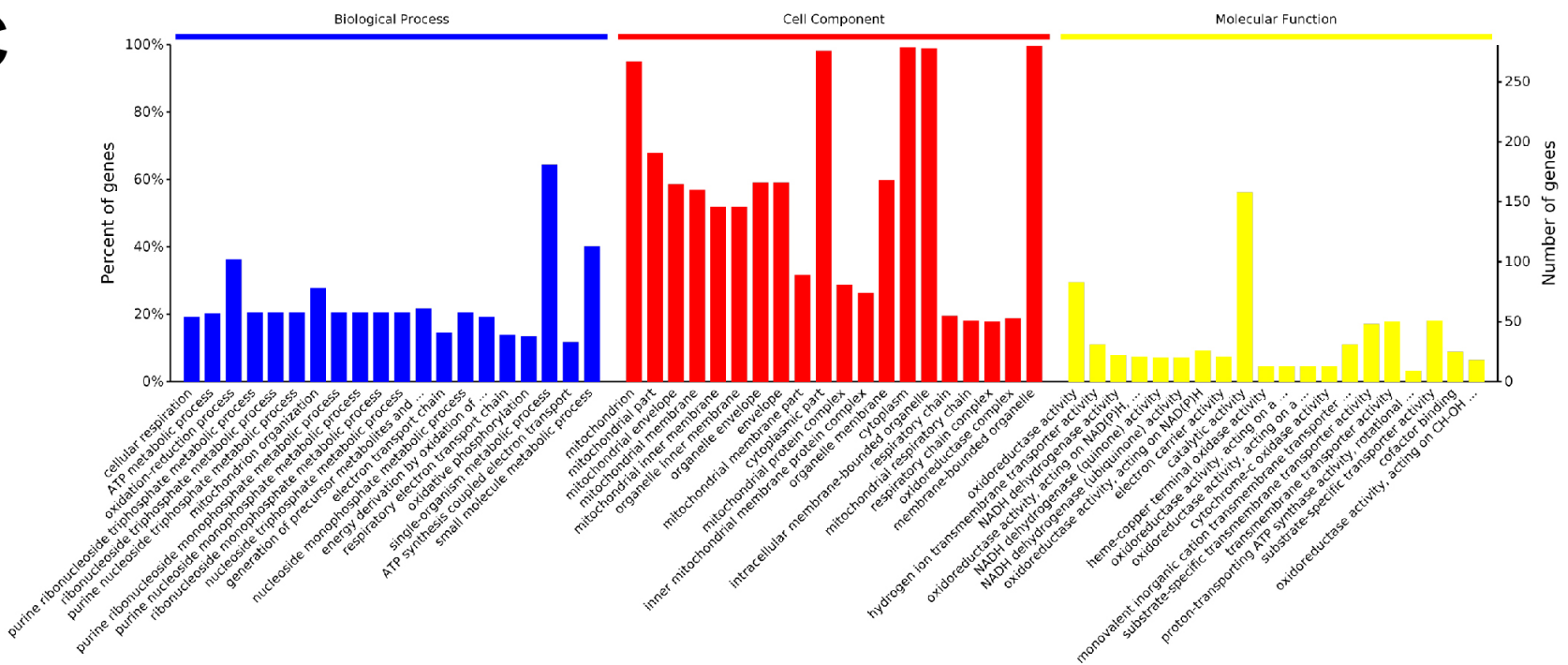

Fig. 2. Gene Ontology (GO) analysis of significantly differentially expressed proteins in the yak-dzo, yak-cattle, and dzo-cattle groups. GO analysis in (groups): A, yak-dzo; B, yak-cattle; and $\mathrm{C}$, dzo-cattle. The entries in each category are sorted by their -log $(P$-value $)$ value from left to right; and the entries on the left side correspond to higher significance. 
A

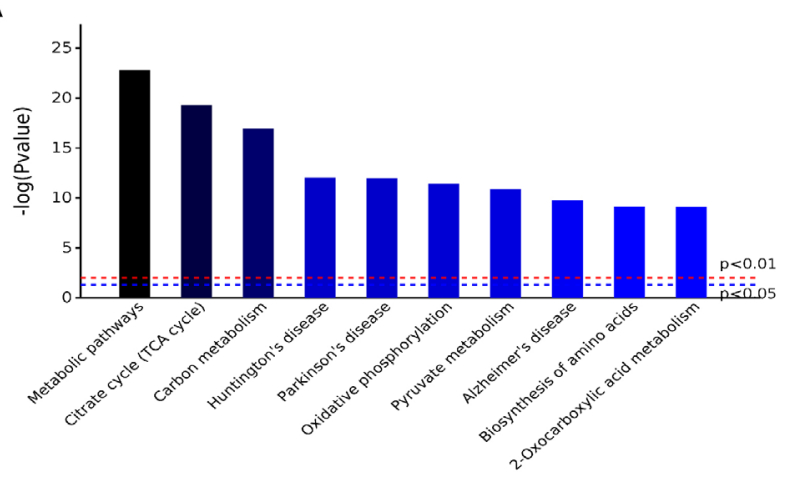

B

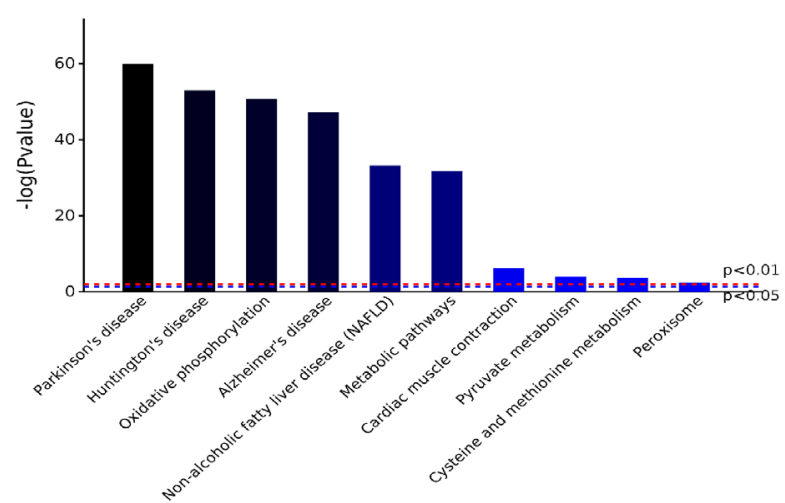

C

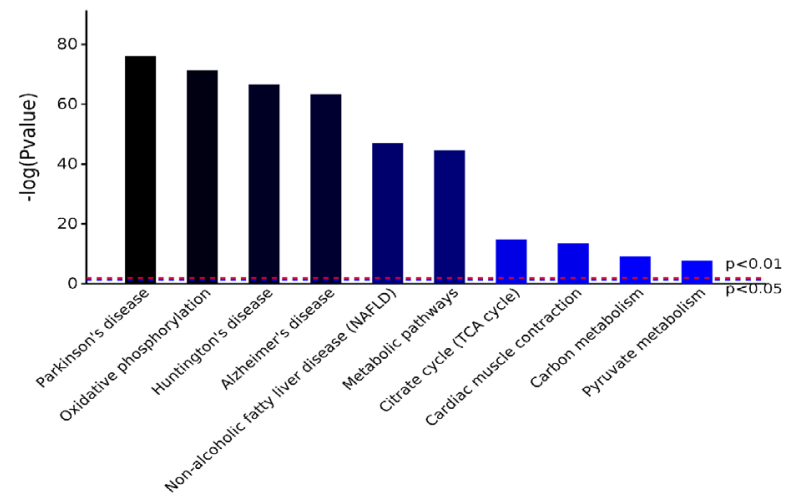

Fig. 3. Enriched Kyoto Encyclopedia of Genes and Genomes (KEGG) pathways of differentially-expressed proteins. KEGG pathways in (groups): A, yak-dzo; B, yak-cattle; and C, dzo-cattle.

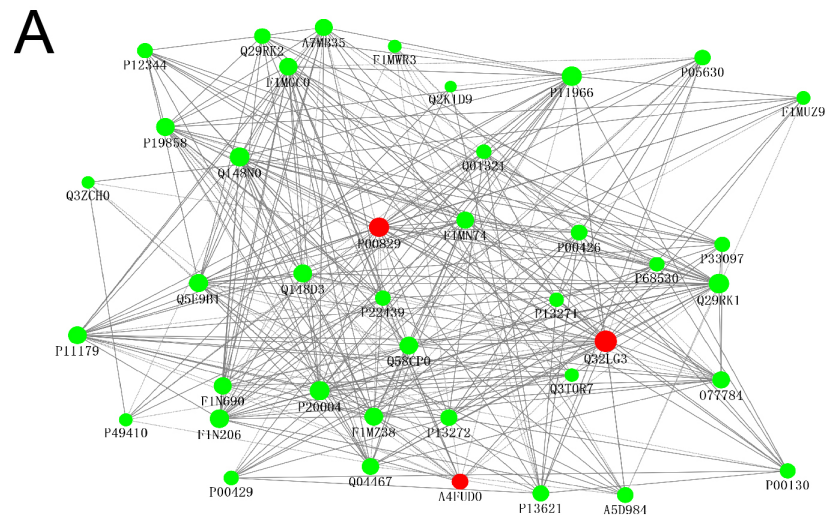

B

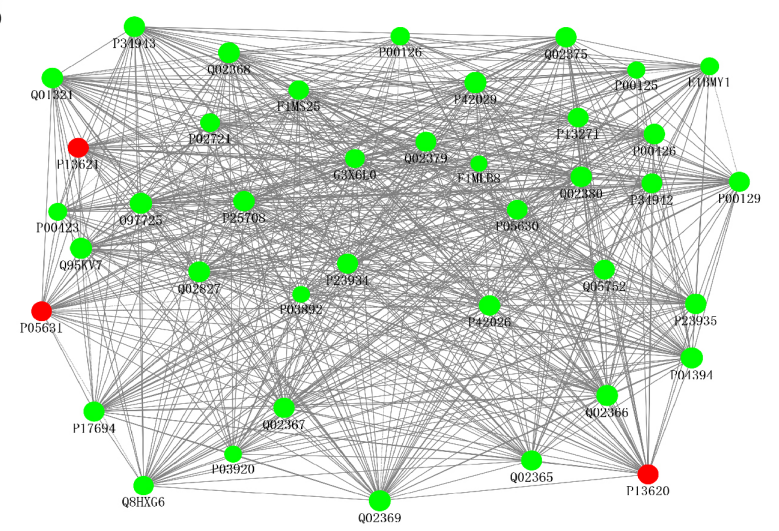

C

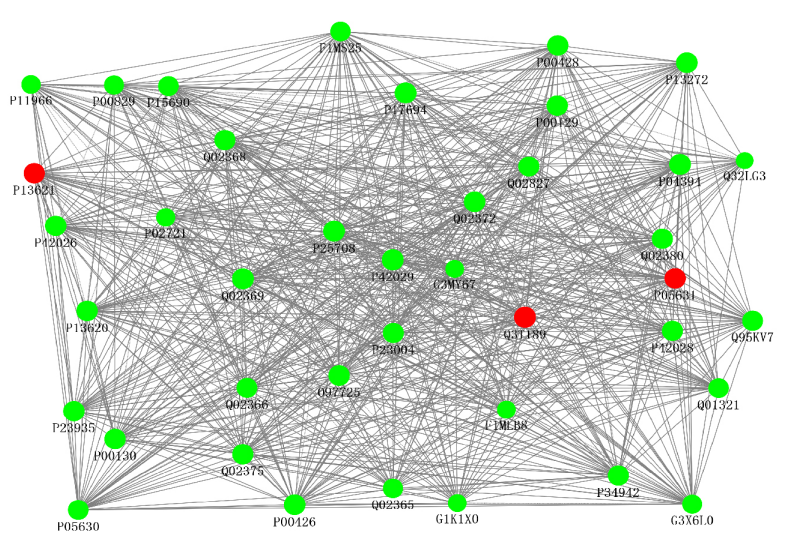

Fig. 4. Top 40 hub proteins represented by the protein-protein interaction (PPI) network. PPI network in (groups): A, yak-dzo; B, yak-cattle; and $\mathrm{C}$, dzo-cattle. The top 3 hub proteins are indicated by red points, and other proteins are indicated by green points.

is known to be necessary for maximal cellular respiration and maintenance of cellular bioenergetics [5, 16, 27]. The cytokine receptor sorting and processing is also controlled by RNF41 and USP8 cross-regulation [7]. Coenzyme Q8A (COQ8A) encodes a mitochondrial protein similar to yeast ATP-binding cassette transporter 1 (ABC1), which functions in a membrane protein complex involved in electron transport in the respiratory chain, and was the protein with the most significant changes in expression in the dzo and cattle groups. Taken together, NRDP1 (RNF41) and COQ8A are expressed at higher levels in yak and dzo compared to that in cattle. Since these proteins are involved in mitochondrial energy metabolism, this may represent the possible mechanism(s) underlying the low-oxygen adaptation observed in yaks.

Among the 3 groups, GO terms were significantly enriched in redox processes and oxidoreductase activities. These processes mainly occur in the mitochondria, and the analysis indicated close association of this organelle to hypoxia adaptation. The most significant pathways identified in the KEGG analysis were Parkinson's disease and metabolic pathways. The yak has enhanced 
oxygen transport and utilization due to high energy generation from the metabolic pathway [39]. Additionally, mitochondrial dysfunction and oxidative stress are known to play important roles in Parkinson's disease [34].

The most enriched hub proteins were ATP5O, ATP5B, ATP5H, ATP5C1, MTHFD1, MDH2, and SDHB. MTHFD1 in the cytoplasm reverses the action of methylenetetrahydrofolate dehydrogenase, and exhibits 3 distinct enzymatic activities in the interconversion of 1-carbon derivatives of tetrahydrofolate [40]. ATP5O, ATP5B, ATP5C1, and ATP5H are related to ATP synthase and hydrogen transport in the mitochondria. MDH2 is the major non-mitochondrial isozyme that catalyzes a step for utilization of C2 compounds [1, 24]. SDH is one of the markers for mitochondrial function, as it is important for the tricarboxylic acid (TCA) cycle. Loss of SDHB expression leads to decreased SDH activity, which causes dysfunction in the mitochondrial TCA cycle, thereby resulting in impaired energy metabolism in tumor cells [11, 38, 44]. These proteins mainly take part in electron transport in the respiratory chain and bioenergy metabolism, which indicate that they may have some contributions in low-oxygen adaptation mechanisms.

In summary, we have identified sets of differentially expressed proteins among yak, dzo, and cattle by LC-MS/MS analysis and provided a comprehensive bioinformatics analysis of these proteins. RNF41 was the protein with the most significant changes in expression in the yak-dzo and yak-cattle groups, while COQ8A was the counterpart identified in the dzo-cattle group. High-altitude hypoxia can regulate the activity of mitochondrial respiratory chain $[29,35,43]$, and change in the mitochondrial structure and function was one of the important mechanisms for animals to overcome the low-oxygen environment. Yak and dzo have a higher endurance capacity than cattle in low-oxygen environment. Comparison of the differentially expressed proteins identified in these 3 groups of related animals facilitates greater understanding of high-altitude hypoxic stress adaptations, which may be useful in reducing the incidence of human high-altitude disease.

CONFLICT OF INTEREST. We declare that we have no financial and personal relationships with other people or organizations that could be construed as an inappropriate influence on our work. Additionally, there is no professional or personal interest of any nature or kind in any product, service, and/or company that could be construed as influencing the position of this work.

ACKNOWLEDGMENTS. This work was supported by grants from the Central Universities Foundation derived from the Northwest Minzu University (Grant no. 31920180134) and the National Science Foundation of China (Grant no. 31560323 and 31360533 ).

\section{REFERENCES}

1. Atzpodien, W., Gancedo, J. M., Duntze, W. and Holzer, H. 1968. Isoenzymes of malate dehydrogenase in Saccharomyces cerevisiae. Eur. J. Biochem. 7: 58-62. [Medline] [CrossRef]

2. Basnyat, B. and Starling, J. M. 2015. Infectious diseases at high altitude. Microbiol. Spectr. 3: 349-357. [Medline] [CrossRef]

3. Beall, C. M., Decker, M. J., Brittenham, G. M., Kushner, I., Gebremedhin, A. and Strohl, K. P. 2002. An Ethiopian pattern of human adaptation to high-altitude hypoxia. Proc. Natl. Acad. Sci. USA 99: 17215-17218. [Medline] [CrossRef]

4. Bernardi, P., Scorrano, L., Colonna, R., Petronilli, V. and Di Lisa, F. 1999. Mitochondria and cell death. Mechanistic aspects and methodological issues. Eur. J. Biochem. 264: 687-701. [Medline] [CrossRef]

5. Bose, A. and Beal, M. F. 2016. Mitochondrial dysfunction in Parkinson's disease. J. Neurochem. 139 Suppl 1: 216-231. [Medline] [CrossRef]

6. Dassanayake, M., Oh, D. H., Haas, J. S., Hernandez, A., Hong, H., Ali, S., Yun, D. J., Bressan, R. A., Zhu, J. K., Bohnert, H. J. and Cheeseman, J. M. 2011. The genome of the extremophile crucifer Thellungiella parvula. Nat. Genet. 43: 913-918. [Medline] [CrossRef]

7. De Ceuninck, L., Wauman, J., Masschaele, D., Peelman, F. and Tavernier, J. 2013. Reciprocal cross-regulation between RNF41 and USP8 controls cytokine receptor sorting and processing. J. Cell Sci. 126: 3770-3781. [Medline] [CrossRef]

8. Dolt, K. S., Mishra, M. K., Karar, J., Baig, M. A., Ahmed, Z. and Pasha, M. A. 2007. cDNA cloning, gene organization and variant specific expression of HIF-1 alpha in high altitude yak (Bos grunniens). Gene 386: 73-80. [Medline] [CrossRef]

9. Elsik, C. G., Tellam, R. L., Worley, K. C., Gibbs, R. A., Muzny, D. M., Weinstock, G. M., Adelson, D. L., Eichler, E. E., Elnitski, L., Guigó, R., Hamernik, D. L., Kappes, S. M., Lewin, H. A., Lynn, D. J., Nicholas, F. W., Reymond, A., Rijnkels, M., Skow, L. C., Zdobnov, E. M., Schook, L., Womack, J., Alioto, T., Antonarakis, S. E., Astashyn, A., Chapple, C. E., Chen, H. C., Chrast, J., Câmara, F., Ermolaeva, O., Henrichsen, C. N., Hlavina, W., Kapustin, Y., Kiryutin, B., Kitts, P., Kokocinski, F., Landrum, M., Maglott, D., Pruitt, K., Sapojnikov, V., Searle, S. M., Solovyev, V., Souvorov, A., Ucla, C., Wyss, C., Anzola, J. M., Gerlach, D., Elhaik, E., Graur, D., Reese, J. T., Edgar, R. C., McEwan, J. C., Payne, G. M., Raison, J. M., Junier, T., Kriventseva, E. V., Eyras, E., Plass, M., Donthu, R., Larkin, D. M., Reecy, J., Yang, M. Q., Chen, L., Cheng, Z., Chitko-McKown, C. G., Liu, G. E., Matukumalli, L. K., Song, J., Zhu, B., Bradley, D. G., Brinkman, F. S., Lau, L. P., Whiteside, M. D., Walker, A., Wheeler, T. T., Casey, T., German, J. B., Lemay, D. G., Maqbool, N. J., Molenaar, A. J., Seo, S., Stothard, P., Baldwin, C. L., Baxter, R., Brinkmeyer-Langford, C. L., Brown, W. C., Childers, C. P., Connelley, T., Ellis, S. A., Fritz, K., Glass, E. J., Herzig, C. T., Iivanainen, A., Lahmers, K. K., Bennett, A. K., Dickens, C. M., Gilbert, J. G., Hagen, D. E., Salih, H., Aerts, J., Caetano, A. R., Dalrymple, B., Garcia, J. F., Gill, C. A., Hiendleder, S. G., Memili, E., Spurlock, D., Williams, J. L., Alexander, L., Brownstein, M. J., Guan, L., Holt, R. A., Jones, S. J., Marra, M. A., Moore, R., Moore, S. S., Roberts, A., Taniguchi, M., Waterman, R. C., Chacko, J., Chandrabose, M. M., Cree, A., Dao, M. D., Dinh, H. H., Gabisi, R. A., Hines, S., Hume, J., Jhangiani, S. N., Joshi, V., Kovar, C. L., Lewis, L. R., Liu, Y. S., Lopez, J., Morgan, M. B., Nguyen, N. B., Okwuonu, G. O., Ruiz, S. J., Santibanez, J., Wright, R. A., Buhay, C., Ding, Y., Dugan-Rocha, S., Herdandez, J., Holder, M., Sabo, A., Egan, A., Goodell, J., Wilczek-Boney, K., Fowler, G. R., Hitchens, M. E., Lozado, R. J., Moen, C., Steffen, D., Warren, J. T., Zhang, J., Chiu, R., Schein, J. E., Durbin, K. J., Havlak, P., Jiang, H., Liu, Y., Qin, X., Ren, Y., Shen, Y., Song, H., Bell, S. N., Davis, C., Johnson, A. J., Lee, S., Nazareth, L. V., Patel, B. M., Pu, L. L., Vattathil, S., Williams, R. L. Jr., Curry, S., Hamilton, C., Sodergren, E., Wheeler, D. A., Barris, W., Bennett, G. L., Eggen, A., Green, R. D., Harhay, G. P., Hobbs, M., Jann, O., Keele, J. W., Kent, M. P., Lien, S., McKay, S. D., McWilliam, S., Ratnakumar, A., Schnabel, R. D., Smith, T., Snelling, W. M., Sonstegard, T. S., Stone, R. T., Sugimoto, Y., Takasuga, A., Taylor, J. F., Van Tassell, C. P., Macneil, M. D., Abatepaulo, A. R., Abbey, C. A., Ahola, V., Almeida, I. G., Amadio, A. F., Anatriello, E., Bahadue, S. M., Biase, F. H., Boldt, C. R., Carroll, J. A., Carvalho, W. A., Cervelatti, E. P., Chacko, E., Chapin, J. E., Cheng, Y., Choi, J., Colley, A. J., de Campos, T. A., De Donato, M., Santos, I. K., de Oliveira, C. J., Deobald, H., Devinoy, E., Donohue, K. 
E., Dovc, P., Eberlein, A., Fitzsimmons, C. J., Franzin, A. M., Garcia, G. R., Genini, S., Gladney, C. J., Grant, J. R., Greaser, M. L., Green, J. A., Hadsell, D. L., Hakimov, H. A., Halgren, R., Harrow, J. L., Hart, E. A., Hastings, N., Hernandez, M., Hu, Z. L., Ingham, A., Iso-Touru, T., Jamis, C., Jensen, K., Kapetis, D., Kerr, T., Khalil, S. S., Khatib, H., Kolbehdari, D., Kumar, C. G., Kumar, D., Leach, R., Lee, J. C., Li, C., Logan, K. M., Malinverni, R., Marques, E., Martin, W. F., Martins, N. F., Maruyama, S. R., Mazza, R., McLean, K. L., Medrano, J. F., Moreno, B. T., Moré, D. D., Muntean, C. T., Nandakumar, H. P., Nogueira, M. F., Olsaker, I., Pant, S. D., Panzitta, F., Pastor, R. C., Poli, M. A., Poslusny, N., Rachagani, S., Ranganathan, S., Razpet, A., Riggs, P. K., Rincon, G., Rodriguez-Osorio, N., Rodriguez-Zas, S. L., Romero, N. E., Rosenwald, A., Sando, L., Schmutz, S. M., Shen, L., Sherman, L., Southey, B. R., Lutzow, Y. S., Sweedler, J. V., Tammen, I., Telugu, B. P., Urbanski, J. M., Utsunomiya, Y. T., Verschoor, C. P., Waardenberg, A. J., Wang, Z., Ward, R., Weikard, R., Welsh, T. H. Jr., White, S. N., Wilming, L. G., Wunderlich, K. R., Yang, J., Zhao F. Q., Bovine Genome Sequencing and Analysis Consortium 2009. The genome sequence of taurine cattle: a window to ruminant biology and evolution. Science 324: 522-528. [Medline] [CrossRef]

10. Fiorini, A., Sultana, R., Barone, E., Cenini, G., Perluigi, M., Mancuso, C., Cai, J., Klein, J. B., St Clair, D. and Butterfield, D. A. 2012. Lack of p53 affects the expression of several brain mitochondrial proteins: insights from proteomics into important pathways regulated by p53. PLoS One 7: e49846. [Medline] [CrossRef]

11. Fishbein, L., Merrill, S., Fraker, D. L., Cohen, D. L. and Nathanson, K. L. 2013. Inherited mutations in pheochromocytoma and paraganglioma: why all patients should be offered genetic testing. Ann. Surg. Oncol. 20: 1444-1450. [Medline] [CrossRef]

12. Ge, R. L., Cai, Q., Shen, Y. Y., San, A., Ma, L., Zhang, Y., Yi, X., Chen, Y., Yang, L., Huang, Y., He, R., Hui, Y., Hao, M., Li, Y., Wang, B., Ou, X., Xu, J., Zhang, Y., Wu, K., Geng, C., Zhou, W., Zhou, T., Irwin, D. M., Yang, Y., Ying, L., Bao, H., Kim, J., Larkin, D. M., Ma, J., Lewin, H. A., Xing, J., Platt, R. N. 2nd., Ray, D. A., Auvil, L., Capitanu, B., Zhang, X., Zhang, G., Murphy, R. W., Wang, J., Zhang, Y. P. and Wang, J. 2013. Draft genome sequence of the Tibetan antelope. Nat. Commun. 4: 1858. [Medline] [CrossRef]

13. Gene Ontology, C. Gene Ontology Consortium 2008. The Gene Ontology project in 2008. Nucleic Acids Res. 36: D440-D444. [Medline] [CrossRef]

14. Giot, L., Bader, J. S., Brouwer, C., Chaudhuri, A., Kuang, B., Li, Y., Hao, Y. L., Ooi, C. E., Godwin, B., Vitols, E., Vijayadamodar, G., Pochart, P., Machineni, H., Welsh, M., Kong, Y., Zerhusen, B., Malcolm, R., Varrone, Z., Collis, A., Minto, M., Burgess, S., McDaniel, L., Stimpson, E., Spriggs, F., Williams, J., Neurath, K., Ioime, N., Agee, M., Voss, E., Furtak, K., Renzulli, R., Aanensen, N., Carrolla, S., Bickelhaupt, E., Lazovatsky, Y., DaSilva, A., Zhong, J., Stanyon, C. A., Finley, R. L. Jr., White, K. P., Braverman, M., Jarvie, T., Gold, S., Leach, M., Knight, J., Shimkets, R. A., McKenna, M. P., Chant, J. and Rothberg, J. M. 2003. A protein interaction map of Drosophila melanogaster. Science 302: 1727-1736. [Medline] [CrossRef]

15. Hassanin, A. and Ropiquet, A. 2004. Molecular phylogeny of the tribe Bovini (Bovidae, Bovinae) and the taxonomic status of the Kouprey, Bos sauveli Urbain 1937. Mol. Phylogenet. Evol. 33: 896-907. [Medline] [CrossRef]

16. Hoekstra, J. G., Montine, K. S., Zhang, J. and Montine, T. J. 2011. Mitochondrial therapeutics in Alzheimer's disease and Parkinson's disease. Alzheimers Res. Ther. 3: 21. [Medline] [CrossRef]

17. Ivy, C. M. and Scott, G. R. 2015. Control of breathing and the circulation in high-altitude mammals and birds. Comp. Biochem. Physiol. A Mol. Integr. Physiol. 186: 66-74. [Medline] [CrossRef]

18. Klemcke, H. G., DeKroon, R. M., Mocanu, M., Robinette, J. B. and Alzate, O. 2013. Cardiac mitochondrial proteomic expression in inbred rat strains divergent in survival time after hemorrhage. Physiol. Genomics 45: 243-255. [Medline] [CrossRef]

19. Li, M., Tian, S., Jin, L., Zhou, G., Li, Y., Zhang, Y., Wang, T., Yeung, C. K., Chen, L., Ma, J., Zhang, J., Jiang, A., Li, J., Zhou, C., Zhang, J., Liu, Y., Sun, X., Zhao, H., Niu, Z., Lou, P., Xian, L., Shen, X., Liu, S., Zhang, S., Zhang, M., Zhu, L., Shuai, S., Bai, L., Tang, G., Liu, H., Jiang, Y., Mai, M., Xiao, J., Wang, X., Zhou, Q., Wang, Z., Stothard, P., Xue, M., Gao, X., Luo, Z., Gu, Y., Zhu, H., Hu, X., Zhao, Y., Plastow, G. S., Wang, J., Jiang, Z., Li, K., Li, N., Li, X. and Li, R. 2013. Genomic analyses identify distinct patterns of selection in domesticated pigs and Tibetan wild boars. Nat. Genet. 45: 1431-1438. [Medline] [CrossRef]

20. Liu, G., Wong, L. and Chua, H. N. 2009. Complex discovery from weighted PPI networks. Bioinformatics 25: 1891-1897. [Medline] [CrossRef]

21. Long, R. J., Dong, S. K., Wei, X. H. and Pu, X. P. 2005. The effect of supplementary feeds on the bodyweight of yaks in cold season. Livest. Prod. Sci. 93: 197-204. [CrossRef]

22. Lorenzo, F. R., Huff, C., Myllymäki, M., Olenchock, B., Swierczek, S., Tashi, T., Gordeuk, V., Wuren, T., Ri-Li, G., McClain, D. A., Khan, T. M., Koul, P. A., Guchhait, P., Salama, M. E., Xing, J., Semenza, G. L., Liberzon, E., Wilson, A., Simonson, T. S., Jorde, L. B., Kaelin, W. G. Jr., Koivunen, P. and Prchal, J. T. 2014. A genetic mechanism for Tibetan high-altitude adaptation. Nat. Genet. 46: 951-956. [Medline] [CrossRef]

23. Luo, Y., Yang, X. and Gao, Y. 2013. Mitochondrial DNA response to high altitude: a new perspective on high-altitude adaptation. Mitochondrial DNA 24: 313-319. [Medline] [CrossRef]

24. Minard, P. 1991. The city and the trades -birth of a corporative language (Turin, 17th-18th Centuries) -French -Cerruti, S. Ann Econ Soc Civil 46: 685-687.

25. Nevo, E. 1999. Mosaic Evolution of Subterranean Mammals, Oxford University Press, Oxford.

26. Olsen, S. J. 1990. Fossil ancestry of the Yak, its cultural significance and domestication in Tibet. Proc. Acad. Nat. Sci. Philadelphia 142: 73-100.

27. Onyango, I. G., Khan, S. M. and Bennett, J. P. Jr. 2017. Mitochondria in the pathophysiology of Alzheimer's and Parkinson's diseases. Front. Biosci. 22: 854-872. [Medline] [CrossRef]

28. Ozawa, T., Sako, Y., Sato, M., Kitamura, T. and Umezawa, Y. 2003. A genetic approach to identifying mitochondrial proteins. Nat. Biotechnol. 21: 287-293. [Medline] [CrossRef]

29. Pialoux, V., Mounier, R., Brown, A. D., Steinback, C. D., Rawling, J. M. and Poulin, M. J. 2009. Relationship between oxidative stress and HIF-1 alpha mRNA during sustained hypoxia in humans. Free Radic. Biol. Med. 46: 321-326. [Medline] [CrossRef]

30. Qiu, Q., Zhang, G., Ma, T., Qian, W., Wang, J., Ye, Z., Cao, C., Hu, Q., Kim, J., Larkin, D. M., Auvil, L., Capitanu, B., Ma, J., Lewin, H. A., Qian, X., Lang, Y., Zhou, R., Wang, L., Wang, K., Xia, J., Liao, S., Pan, S., Lu, X., Hou, H., Wang, Y., Zang, X., Yin, Y., Ma, H., Zhang, J., Wang, Z., Zhang, Y., Zhang, D., Yonezawa, T., Hasegawa, M., Zhong, Y., Liu, W., Zhang, Y., Huang, Z., Zhang, S., Long, R., Yang, H., Wang, J., Lenstra, J. A., Cooper, D. N., Wu, Y., Wang, J., Shi, P., Wang, J. and Liu, J. 2012. The yak genome and adaptation to life at high altitude. Nat. Genet. 44: 946-949. [Medline] [CrossRef]

31. Schon, E. A. 2000. Mitochondrial genetics and disease. Trends Biochem. Sci. 25: 555-560. [Medline] [CrossRef]

32. Shannon, P., Markiel, A., Ozier, O., Baliga, N. S., Wang, J. T., Ramage, D., Amin, N., Schwikowski, B. and Ideker, T. 2003. Cytoscape: a software environment for integrated models of biomolecular interaction networks. Genome Res. 13: 2498-2504. [Medline] [CrossRef]

33. Simonson, T. S., Yang, Y., Huff, C. D., Yun, H., Qin, G., Witherspoon, D. J., Bai, Z., Lorenzo, F. R., Xing, J., Jorde, L. B., Prchal, J. T. and Ge, R. 2010. Genetic evidence for high-altitude adaptation in Tibet. Science 329: 72-75. [Medline] [CrossRef]

34. Subramaniam, S. R. and Chesselet, M. F. 2013. Mitochondrial dysfunction and oxidative stress in Parkinson's disease. Prog. Neurobiol. 106-107: 17-32. [Medline] [CrossRef] 
35. Taylor, C. T. 2008. Mitochondria and cellular oxygen sensing in the HIF pathway. Biochem. J. 409: 19-26. [Medline] [CrossRef]

36. Taylor, S. W., Fahy, E., Zhang, B., Glenn, G. M., Warnock, D. E., Wiley, S., Murphy, A. N., Gaucher, S. P., Capaldi, R. A., Gibson, B. W. and Ghosh, S. S. 2003. Characterization of the human heart mitochondrial proteome. Nat. Biotechnol. 21: 281-286. [Medline] [CrossRef]

37. Taylor, S. W., Warnock, D. E., Glenn, G. M., Zhang, B., Fahy, E., Gaucher, S. P., Capaldi, R. A., Gibson, B. W. and Ghosh, S. S. 2002. An alternative strategy to determine the mitochondrial proteome using sucrose gradient fractionation and 1D PAGE on highly purified human heart mitochondria. J. Proteome Res. 1: 451-458. [Medline] [CrossRef]

38. van Hulsteijn, L. T., Dekkers, O. M., Hes, F. J., Smit, J. W. and Corssmit, E. P. 2012. Risk of malignant paraganglioma in SDHB-mutation and SDHD-mutation carriers: a systematic review and meta-analysis. J. Med. Genet. 49: 768-776. [Medline] [CrossRef]

39. Wang, H. C., Long, R. J., Liang, J. B., Guo, X. S., Ding, L. M. and Shang, Z. H. 2011. Comparison of nitrogen metabolism in yak (Bos grunniens) and indigenous cattle (Bos taurus) on the Qinghai-Tibetan plateau. Asian Austral. J. Anim 24: 766-773. [CrossRef]

40. Watkins, D., Schwartzentruber, J. A., Ganesh, J., Orange, J. S., Kaplan, B. S., Nunez, L. D., Majewski, J. and Rosenblatt, D. S. 2011. Novel inborn error of folate metabolism: identification by exome capture and sequencing of mutations in the MTHFD1 gene in a single proband. J. Med. Genet. 48: 590-592. [Medline] [CrossRef]

41. Wiener, G., Han, J. L. and Long, R. J. 2003. Regional Office for Asia and the Pacific Food and Agriculture Organization of the United Nations. 2nd ed., Bangkok.

42. Wu, X., Yen, L., Irwin, L., Sweeney, C. and Carraway, K. L. 3rd. 2004. Stabilization of the E3 ubiquitin ligase Nrdp1 by the deubiquitinating enzyme USP8. Mol. Cell. Biol. 24: 7748-7757. [Medline] [CrossRef]

43. Yagi, T. and Matsuno-Yagi, A. 2003. The proton-translocating NADH-quinone oxidoreductase in the respiratory chain: the secret unlocked. Biochemistry 42: 2266-2274. [Medline] [CrossRef]

44. Yang, C., Matro, J. C., Huntoon, K. M., Ye, D. Y., Huynh, T. T., Fliedner, S. M. J., Breza, J., Zhuang, Z. and Pacak, K. 2012. Missense mutations in the human SDHB gene increase protein degradation without altering intrinsic enzymatic function. FASEB J. 26: 4506-4516. [Medline] [CrossRef] 